\title{
Sexual Practices and Perceptions of Risk among Undergraduate Students Attending a Tertiary Institution in Jamaica: A Pilot Study
}

\author{
Andrea Pusey-Murray1, Cynthia Onyefulu² \\ ${ }^{1}$ Caribbean School of Nursing, University of Technology, Kingston, Jamaica \\ ${ }^{2}$ Faculty of Education \& Liberal Studies, University of Technology, Kingston, Jamaica \\ Email: Andrea.Pusey-Murray@utech.edu.jm
}

Received 18 January 2015; accepted 2 February 2015; published 6 February 2015

Copyright (C) 2015 by authors and OALib.

This work is licensed under the Creative Commons Attribution International License (CC BY). http://creativecommons.org/licenses/by/4.0/

(c) (i) Open Access

\section{Abstract}

This paper describes the sexual practices and perceptions of risk among undergraduate students attending a tertiary institution in Jamaica. The study was guided by six research questions. To answer these research questions, a descriptive survey design was used for the study. A total of 63 undergraduate students were selected using the stratified random method. Data for the study were collected through the use of a questionnaire and focus group discussion. The data were coded and entered into SPSS version 20. Simple descriptive statistics (frequency and percentage, cross-tabulation and t-test) were used to analyze the data. The results showed that over twothirds (85\%) of the students were sexually active and that the male students initiated their sexual activities earlier than the female students. It was revealed that $12.6 \%$ of the respondents had their first sexual encounter when they were less than ten years old. The findings of this study showed that a greater number of females $(\mathbf{4 1 . 0 \% )}$ ) reported using a condom on their first sexual encounter when compared to $20.6 \%$ of the male undergraduate students. Although $88.8 \%$ of the respondents reported seeing the promotional advertisement about safe sex, $11.2 \%$ stated that the advertisements were not convincing, for example they stated: "it did not convince me, and needed to show more than the risk", and "not doing enough to scare young people about STD". This has serious implications for how prevention messages are fashioned. The study indicates the need for partnerships to improve the STI/HIV risk reduction interventions in Jamaica. Based on the sexual practices identified in this study, undergraduates at this particular university are at risk of contracting STIs making them susceptible to cervical cancers, infertility and unwanted pregnancies. Based on the findings and their implications, six recommendations were made on how to use the platforms that will appeal to this group of undergraduate students in practicing safe sex.

\section{Keywords}

Sexual Practices, Perceptions, Risk, Undergraduate Students 


\section{Introduction}

Currently, research in human sexuality remains largely focused on the potentially negative outcome of sexual expression. Adolescents and young adults represent a large and growing proportion of the population of developing countries such as Jamaica. The sexual and reproductive health of young people is under threat in part because of their perceived lack of vulnerability to Sexually Transmitted Infections (STIs), including Acquired Immunodeficiency Syndrome (AIDS). According to Figueroa, Fox and Minor [1] "lower socio-economic status and or lower level of educational attainment are well recognized as generally associated with risky sexual behaviors” [2]. Early sexual activity, combined with a lack of relevant information, services and skills to avoid risky situations, place Jamaican young adults at risk of unintended pregnancies, STIs including human immunodeficiency virus (HIV) and other threats to their sexual and reproductive health [3]. Estimates suggest that about $48 \%$ of the nearly 19 million cases of STDs occurring annually in the United States are acquired by persons aged 15 - 24 years [4]. Sequelae of Chlamydia Trachomatis and Neisseria Gonorrhea, for example, include infertility and pelvic inflammatory disease [5].

Human Immunodeficiency Virus (HIV) Infection and Acquired Immune Deficiency Syndrome (AIDS) affect all aspects of human endeavors as they cut across age, gender, race, socio-political status, education, relation, ethnic, culture, and barriers of any kind. As of 2005, about 43 million have been infected with the dreaded virus while over 25 million have died of the infection world-wide. Despite over three decades of related research and intervention, the global epidemic of human immunodeficiency virus (HIV) infection continues to afflict more than 33 million people worldwide [6].

Sexual practices that are associated with risky behaviours place individuals at risk for several sexually transmitted infections (STIs) inclusive of HIV/AIDS. In the Jamaican population approximately $79 \%$ of all AIDS cases reported in 2009 are in the 20 - 49 year old age group (compared to 69\% in 2008) [7]. University students are among the age group who may be engaging in risky sexual practices. HIV/AIDS represents a serious health threat in Jamaica.

The purpose therefore is to explore university students' perceptions about their sexual practices and perceptions about their risky sexual decisions. High-risk sexual behaviours are prevalent in tertiary educational institutions, but little is known about the social influences that bear on the reproductive health decision-making and behaviour of the undergraduates. An increasing number of young persons during their most productive years are having STIs including HIV infection and unplanned pregnancies due to risky sexual practices. This has resulted in the need to investigate what underlies their sexual practices and the perceptions that they hold about risky sexual decisions.

The following research questions guided the study.

\subsection{Research Questions}

The following research questions will be answered:

1) Which sub-groups (gender, age, and status) of students are more exposed to risky sexual practices?

2) To what extent are the undergraduate students' perceptions of risk associated with their sexual practices?

3) What types of safeguards are used by the students to protect themselves against STI's?

4) What percentage of undergraduate students is at risk of contracting Sexually Transmitted Infections? To what extent are the existing sexual and reproductive health campaigns in Jamaica effective in promoting acceptable/good sexual practices among undergraduate students?

5) What factors (parental, peer pressure, personal beliefs, social practices, etc.) contribute to risky sexual practices among undergraduate students?

\subsection{Literature Review}

Sexually transmitted infections, including HIV/AIDS have become one of the most devastating diseases humanity has ever faced. It has become a major public health concern with about half of new infections occurring in young people [8]. Sexual behavior change remains the most effective way of preventing transmission. A number 
of behavior change theories that recognize the complexity of human behavior and other structural factors that make people vulnerable have been suggested [9]. Some of theories include AIDS Risk Reduction Model and the Health Belief Model (HBM). These models are of great importance in the development of HIV/AIDS programs [8].

Health Belief Model. The HBM is psychological model that aids in predicting and explaining behaviors. The HBM postulates that individual behavior changes are based on how serious a person believes the perceived threat of contracting the disease or illness is. If the perceived threat is high, then there is a greater probability that the individual will adhere to the recommendations in order to reduce the threat [10]. Besides perceived susceptibility to health threats, other main principles or components of HBM include perceived severity to health threats, perceived barriers that may cause an individual to not be able to adhere to the proposed recommendations, perceived benefits of engaging in the recommendations and cues to action [11]. Bandura's self-efficacy theory later became an added component to HBM. In order to to increase the model's explanatory power [12]. According to Freimuth [13]:

The model suggests that readiness to engage in a health behavior follows from a perceived threat of disease, coming from an individual's perception of his or her susceptibility to the disease and its potential severity. The cue for action is a triggering device stimulated by a private perception or by communication from the media or other people. Behavior is evaluated from an estimate of the potential benefits of engaging in the recommended health behavior to reduce susceptibility or severity. The benefits are then weighed against perceptions of physical, psychological, financial, and other costs or barriers inherent in the recommended health behavior. Demographic, social, structural, and personality factors are included in the model because they are believed to indirectly influence behavior. (p. 100).

Survey-based research that has tested principles of the HBM against knowledge, attitudes, and behaviors associated with HIV/AIDS risk has found that perceptions of the disease can have an impact on a person's behavior [14]. An important factor in the spread of HIV/AIDS is believed to be poor knowledge about how it is spread and how it can be prevented. The utility of the Health Belief Model (HBM) continues to be suggested in identifying preventive behaviors.

A study conducted by Crawford, and his colleagues [15], showed that the use of condoms was highest among those with two to three partners (56.7\%) and least among those with four and more partners (1.9\%). Condom use was also highest in the 30 - 35 age groups. The respondents with two to three sexual partners ranked highest among those with STIs (85.9\%) and least among those with four or more partners (1.6\%). The use of other contraceptive methods was prevalent among those who had one sexual partner, $12.5 \%$ of those who had contracted STIs. The non-use of contraceptives was highest among those with one sex partner (53.4\%), followed by those who had two to three partners (45.1\%) and least among those with 4 or more partners (1.5\%). The findings of this study confirmed a high level of sexual activity among young adults in Jamaica.

The multiple sexual partner rate among Nigerian university students was 3.5 sexual partners on average, while $63 \%$ of Togolese university students had more than one sexual partner. Similarly, at the Malawi University, $40.4 \%$ of students reported having multiple sex partners in the last 12 months [16] [17].

Within the HBM framework, perceived benefits and barriers of safer sex are predictive of both condom use intentions and behavior, but students' beliefs and attitudes toward HIV did not influence their decision to use condoms [18] [19], whereas the attitudes toward condoms and perceived vulnerability to HIV significantly correlated with condom use among white [20], Asian-American [21], and Hispanic [22]. However, attitudes toward condoms did not predict sex partners or condom use among college women [23]. Among African-Americans, perceived barriers to safer sex and gender significantly predicted condom use, and condom use increased when perceived barriers were controlled in the model for men [24]. African-American and Hispanic college students are at even higher risk of HIV, compared to white students, because they fail to carry out safer sex interventions due to their partners' attitude toward condoms [25]. In addition, college men reported more negative attitudes toward condoms regarding sexual pleasure when compared to women [26].

Although African-American students are projected by some to be the next group most significantly affected by the HIV epidemic, both genders expressed negative views of condoms and this attitude is the primary barrier to safer sex [27]. "Living for the moment" and "feeling invincible" also impact their willingness to use condoms and are typical of attitudes of the college population [27]. At the same time black women believe they are at higher risk of HIV because their partners have more sex partners and because they do not use condoms due to their male partners' preferences [28]. 
A convenience sample of 421 from the undergraduate population was found on the Department of Research, Planning, and Institutional Effectiveness (RPIE) website [29], by Pavlich, [30], indicated that 38\% of participants had their first sexual intercourse between the ages of 17 and 19. Of the students who were sexually active, $30.6 \%$ reported using condoms as their method of birth control, $24.2 \%$ used birth control pills to prevent pregnancy, $5.9 \%$ practiced withdrawal, and $14.7 \%$ used no method of prevention. Only $36.1 \%$ of students inquired about, or have been tested by a doctor or nurse practitioner for STI's. Furthermore, [30] they stated that, only $46 \%$ of the participants received information on campus while $50 \%$ did not receive information on campus. Participants stated that they had received information from a variety of sources including college classes, residence halls or campus housing, student clubs and organizations, the Student Health Center, health fairs, pamphlets or brochures distributed on campus from a variety of sources, the university newspaper, and informal discussions with friends. The majority of respondents stated that they had received information from college classes and from pamphlets or brochures.

In a qualitative study conducted by Tangmunkongvorakul, Carmichael, Banwell, Utomo, and Sleigh [31] among more than 1750 young Northern Thai people aged 17 - 20 years the data yielded evidence confirming that girls often were unable to negotiate protected sex, and boys failed to fully appreciate the potential negative consequences of their sexual behaviour.

Talking about a serious issue like this [protected sex] is very hard for me. I had a lesson with my ex-boyfriend. I really wanted him to use condoms. I talked to him frankly, but he didn't say anything. His reaction was very disappointing. When I said no to having sex when he didn't bring a condom, he really got in a bad mood. It was a very uncomfortable situation. So with my current boyfriend, if he doesn't bring a condom we use some other method. I don't want to be fussy about this any more. (Nook, female, 20 years, university student)

Some reasoned that their partners were virgins when they met; hence, protection to avoid disease was not needed. Others stated that loyalty and mutual intimacy created trust, and ensured there was no risk of STD or HIV infection.

We know that using condoms can protect us from getting AIDS or STDs. If we think we are at risk, we should use them. Everyone knows that. But at the time of having sex, we kind of forget everything (laughing). (Male focus group discussant, 18 - 20 years, technical school)

We are told condoms are good for protection. But I don't see many boys carrying them.

Maybe it's hard to find free condoms, or the boys can't afford to buy them. I think condom use is good in theory, but in the real world I can guarantee that no one uses them all the time. That's impossible. (Female focus group discussant, 18 - 20 years neighbourhood community) p. 332.

A cross-sectional online survey was conducted among the 16 - 26 years age group, $n=906$ by Herman [32] The findings indicated that $91.4 \%$ had at least one sexual partner in the last 6 months and $67.4 \%$ had unprotected sex with any partner in the past six months. Of the individuals who had unprotected sex in the last 6 months, 83.3\% had had unprotected sex with a regular partner, and 36.8\% had had unprotected sex with a casual partner. Only $58.3 \%$ of the participants, who had unprotected intercourse in the last six months, had ever been tested for STIs. Half of the sample (50.3\%) had an STI test done. Only about one third (36.8\%) of the participants had ever had an STI test as well as an HIV test and $13.6 \%$ had only tested for STIs. Of the respondents who had ever tested for STIs, one quarter (22.6 \%) had tested less than three months before the study, and one quarter had tested 4 - 6 months before (26.8\%). The other half of the participants who had ever tested for STIs had tested either between 7 - 12 months before (23.2\%), or more than 12 months before (27.4\%).

Mahoney, Thombs and Ford [33] conducted a cross-sectional study and the data showed that the mean score of perceived susceptibility was 21.19 (out of 32) and it was 12.47 (out of 24) for perceived severity. Also the mean scores of perceived benefits and barriers were 9.05 and 9.45 (out of 12 and 16, respectively). The respondents acquired $46.61 \%$ of total knowledge score, $66.21 \%$ of perceived susceptibility, $51.95 \%$ of perceived severity, $75.41 \%$ of perceived benefits and $59.06 \%$ of perceived barriers. The authors found a positive association between knowledge and perceived susceptibility. The results of this study revealed that participants' mean scores of perceived severity of HIV/AIDS were near average. These results also revealed that the participants did not believe that they were at high risk of HIV/AIDS. Having such a belief, students do not try to prevent HIV/AIDS. There was a significant difference between mean scores of knowledge and perceived susceptibility and educational field of participants ( $\mathrm{p}<0.001$ ) as cited in Baghianimoghaddam, Rahaii, and Khani [34].

Seloilwe [35] surveyed 1327 students at the University of Botswana in the academic year 1999/2000 to investigate factors influencing the spread of HIV. The study revealed that some students changed partners three to 
four times in a year; the respondents reported that they sometimes changed partners to acquire material gain, such as money, gifts, clothing and cell phones (as cited in Abels and Blignaut, [36]. Kaufman and Stavrou, [37] defined transactional sex as, "exchanging sexual intercourse for money, gifts, favours, or other material or nonmaterial items" (as cited in Abels and Blignaut, [36] p. 256). However, MacPhail and Campbell [36] found that transactional sex among South African youths from a mining town was an exception. Many of the youths stated that they expected gifts in the course of their relationship and claimed their relationships were not a source of income per se, although, Kaufman and Stavrou [38] postulated that "gift-giving may be viewed as commonplace among same-age adolescents, a part of courtship, and a means with which to establish a relationship and intimacy" (p. 256).

\section{Research Methodology}

A cross-sectional survey research design was used for the study. According to Creswell [39], in a cross-sectional survey research design, the researcher collects data at one point in time to examine current attitudes, beliefs, opinions, or practices, among other things. Ethical clearance was received from the Research and Ethics Committee of the university.

Students who were used in this study were from the main campus and were selected using the stratified random proportionate method. See Table 1 for the distribution of students used in the study.

Of the 63 undergraduate students who participated, 21 (33.3\%) were in the second year of their study, 21 (33.3\%) in third year, and another 21 (33.3\%) in the fourth year. One participant did not respond to this item. In terms of the participants' marital status, the findings showed that $49(76.6 \%)$ of the undergraduate students who participated in the study were single. This was followed by 9 (14.1\%) who were married, two or three percent divorced $1(1.6 \%)$ in a common-law relation and two or three percent was separated.

The questionnaire was used for the collection of data. This is because, Leedy and Ormrod [40] recommended the questionnaire as one of the data collection methods for survey research. The questionnaire had four sections and a total of sixty three items. Section A contained ten demographic items on gender, age-range, current employment status, marital status, faculty, undergraduate program enrolled in, status, residence, with, religious affiliation and active member of religious affiliation. Each of these items had responses which allowed the participants to choose from the option that suited their response to the item. Section B had twenty-two items, which measured the undergraduate students' relationship and dating behaviours. These items had multiple response formats which allowed students to select the response that reflected their views. Section C had three items, which measured the undergraduate students' perception of the influence that campaigns had on their sexual practices and perceptions of risk. Section D had twenty eight Likert type items, which measured the undergraduate students' perceptions of sexual behavior and experiences. The questionnaire was coded and entered into SPSS version 20. Simple descriptive statistics (frequency and percentage, and cross-tabulation) was used to analyze the data.

Focus Group Discussion. A focus group discussion guide with five open-ended questions was used to guide the focus group. The purpose of the focus group as a data collection tool of the study was to explore university students' perceptions of sexual practices and the perceptions that they held about risky sexual decisions. The focus group was conducted with five consenting participants, in order to establish and verify information that was acquired through the self administered questionnaires. The participants' ages ranged from 19 to 32 years. The results presented here are set out under six broad categories namely: definition of sexually transmitted diseases, impact of sexually transmitted diseases on health, condoms as a protective device against STIs, sufficiently educated on risky sexual practices by parents, effectiveness of media campaigns and the impact of the

Table 1. Participants by Gender and Age.

\begin{tabular}{cccc}
\hline Age-Range & \multicolumn{2}{c}{ Gender } & Total \\
\cline { 2 - 4 } & Male & Female & $42(66 \%)$ \\
26 - 25 years & $17(26 \%)$ & $25(39 \%)$ & $16(25 \%)$ \\
35 years & $7(11 \%)$ & $9(14 \%)$ & $(8 \%)$ \\
46 - 55 years & $2(3 \%)$ & $2(3 \%)$ & $1(1 \%)$ \\
Total & - & $1(1 \%)$ & $63(100 \%)$ \\
\hline
\end{tabular}


sexually transmitted infections campaign on their behaviours.

The researcher adhered to ethical principles by ensuring that the participants gave their consent before data were collected. Further, participants identities were protected, and the right to privacy were maintained.

\section{Findings}

The findings of the study are presented in this section under six themes: students' exposed to risky sexual practices, students' perceptions of risk associated with their sexual practices, safeguards used by undergraduate students to protect themselves against sexually transmitted infections, risk in contracting sexually transmitted infections, existing sexual and reproductive campaigns and factors contributing to risky sexual practices among undergraduate students.

\section{Students' Exposed to Risky Sexual Practices}

Research Question One: Which sub-groups (gender, age, and status) of students are more exposed to risky sexual practices?

Ten questions in the questionnaire were used to provide answers to this research question. The participants were asked the age at which they had had their first sexual encounter. The findings showed that eight or (12.6\%) of the undergraduate students had their first sexual encounter between the ages of five and ten, 40 (63\%) between the ages of twelve and nineteen and 9 (14\%) between ages 20 and twenty-five. Six participants did not respond to this item. The findings also showed that of the number of males who indicated that they did not use condoms on their first sexual encounter, eight or (12.6\%) when compared to the seven or $11 \%$ of the females was not significant. However, there was a greater number of females $26(41 \%)$ who reported using condoms on their first sexual encounter when compared to 13 (20.6 \%) of the male undergraduate students. Four participants did not respond to this item. The findings further revealed that $12(19 \%)$ of those who were single had changed 2 - 3 partners within six months, while two or 3.1\% who were married had changed between 4 - 6 partners within six months. Eight participants did not respond to this question.

\section{Students' Perceptions of Risk Associated with their Sexual Practices}

Research Question Two: To what extent are the undergraduate students' perceptions of risk associated with their sexual behaviours?

To answer the above research question, twelve questions were asked in the questionnaire used to collect data from the participants. The participants were asked to indicate who they were sexually attracted to. The findings showed that $52 \%$ or $82.5 \%$ were attracted to the opposite sex while $4(6.3 \%)$ of the undergraduate students, that is, an equal number of the male and female participants indicated that they were attracted to the same sex, and three or $4.7 \%$ were sexually attracted to both sexes. The undergraduate male students were also asked if they were concerned about their partners becoming pregnant. Twenty seven 27 (57.5\%) stated "yes" while 11 (42.5\%) stated "no". When asked how often they used a condom when having sex with their regular partners 13 (20.6\%) stated "no regular partner", 8 (12.6\%) stated "never", 17 (26.9\%) sometime within the month while 16 (25.3\%) stated "every time". Of the 13 undergraduate students who stated that they did not use condoms with their regular partners, seven or $11 \%$ were males and six or $9.5 \%$ were females. Of note these seven or $11 \%$ were second year students. Twenty-four or (38\%) of the undergraduate students surveyed stated that they had been tested for sexually transmitted infections while 35 or $55.5 \%$ stated "no". Four did not respond to this item. Of the 24 students 15 (23.8\%) were males and nine or $14.2 \%$ were females, while of the 35 students 21 or $33.3 \%$ were males and 14 or $22.2 \%$ were females.

\section{Safeguards Used by Undergraduates to Protect Themselves against Sexually Transmitted Infections}

Research Question Three: What types of safeguards are used by the students to protect themselves against STI's? In the questionnaire, the undergraduate students were asked which contraceptive they had used in the past six months. The findings revealed that 42 (66.6\%) had used condoms, 9 (14.2\%) abstained, 2 (3.1\%) used intrauterine devices while 4 (6.3\%) used depo-provera injections. Of the nine who chose the abstinence method four or $6.3 \%$ were males and five or $7.9 \%$ were females; seven or $11.1 \%$ were single, one or $1.5 \%$ married and one or 
$1.5 \%$ was divorced. Of note was that six or 9.5\% were between the ages of 18 - 25 years, 2 (3.1\%) between 26 35 years and one or $1.55 \%$ was between 36 - 45 years. Of the nine who abstained five or $7.9 \%$ were second year, one $(1.5 \%)$ third year and three or $4.7 \%$ were fourth year undergraduate students.

The students when asked to give their views on condoms as a protective device gave answers which spoke of their effectiveness as well as their ability to prevent unplanned pregnancies.

Condoms are very effective. It decreases the susceptibility and minimizes the portal of entry of the organism. It may not serve as a protective device if the date on condom is expired because it might burst and the organism is passed on to the individual. Female 20 years old.

Safest practice as it relates to sexually transmitted infections. The pill doesn't provide a barrier as it relates to blocking the portal of entry. It is a problem sometimes because it takes away the skin to skin pleasure. Female 19 years old.

It is very effective. They don't protect one $100 \%$ but it reduces somewhat the risk of one catching the disease. There is a stigma using condom. Some persons believe that if they have a STI then they cannot be cured because they must go bare back. My partner says it doesn't give him any satisfaction and I will try to say let the condom stay but he would threaten me that he will leave so I take it off unwillingly and do a lot of fretting. Female 32 years old.

It is a very effective way in preventing STI however there is the dental condom which is used when one is performing oral sex. These are uncomfortable because it has a thick ring which is usually inserted which is a big deterrent in using it and being protected against STI. Female 25 years old.

It prevents unplanned pregnancy and it is $99 \%$ effective as some condoms do burst and one can inherit the disease. Furthermore persons are allergic to the latex condom hence they shy away from using same. Male 29 years old.

\section{Risks in Contracting Sexually Transmitted Infections}

Research Question Four: What percentage of undergraduate students is at risk of contracting Sexually Transmitted Infections?

When asked if a condom ever broke during sexual intercourse 35 (54.7\%) stated "yes" while 17 (26.6\%) stated "no". Of the 35 who reported that the condom broke; 18 (51.4\%) were males and 17 (48.5\%) were females.

When asked how many times they ran the risk of contracting sexually transmitted infections, 22 (34.9\%) stated "never" 11 (17.4\%) stated "once" 10 (15.8\%) stated "twice" 10 (15.8\% ) more than thrice. Of the 22 undergraduate students that stated they were never at risk for contracting sexually transmitted infections, 17 were females and five were males. The findings further indicated that of these 22 undergraduates six or $9.5 \%$ were second years, six or $9.5 \%$ third years and 10 (15.8\%) were fourth years. Eight participants did not respond to this item.

When the students were asked if they felt they were at risk in contracting sexually transmitted infections as a result of sexual abuse 23 (36.5\%) stated "yes" while 27 (42.8\%) stated "no". Of the 23 who felt they were at risk because of sexual abuse, $14(22.2 \%)$ were within the 18 - 25 year group, $7 \%$ or $11.1 \%$ were between the ages of 26 - 35 years, while 2 or $3.1 \%$ were in the 36 - 45 year age group. The findings showed that 17 (26.9\%) were single, $4 \%$ or $6.3 \%$ were married one or $1.5 \%$ was divorced and one or $1.5 \%$ was separated. Thirteen participants did not respond to this item.

When the students were asked if they felt they were at risk in contracting sexually transmitted infections as a result of having sex without a condom 36 (57.1\%) stated "yes" while 19 (25.3\%) stated "no". Eight participants did not respond to this item.

Of the 36 (57.1\%) who felt they were at risk because of not using a condom during sexual intercourse, 23 (36.5\%) were within the 18 - 25 year group, 10 (15.8\%) 26 - 35, and 3 (4.7\%) the 36 - 45 years age group. The findings showed that 29 (46\%) were single, and 9 (14.2\%) were married. The findings further indicated that 16 (25.3\%) were second year, 11 (17.4\%) third year and 9 (14.2\%) fourth year undergraduate students.

Of the 25 (39.6\%) who felt they were at risk because of not using a condom during sexual intercourse, 14 (22.2\%) were between 18 and 25 years, 7 (11.1\%) 26 - 35 years, 2 (3.1\%) 36 - 45 years age group. The findings showed that $25(39.6 \%)$ were single, and $9(14.2 \%)$ were married. They further showed that 10 (15.8\%) were second year, $8(12.6 \%)$ third year and 7 (11.1\%) fourth year undergraduate students. 
Research Question Five: To what extent are the existing sexual and reproductive health campaigns in Jamaica effective in promoting healthy sexual practices among undergraduate students?

The most popular source of information stated by the students was the mass media (34.9\%). This was followed by their teachers (26.9\%), radio (22.2\%) and parents (7\%).

When asked if they had seen any promotional advertisement about safe sex, 56 (88.8\%) stated "yes" and 5 (7.9\%) stated "no".

Of the 56 undergraduate students who responded that they had seen a promotional advertisement about safe sex, the majority stated that it reduced the risk of contracting sexually transmitted infections. [It] "reinforced what I already knew”, “convinced me by highlighting all the risks that goes with unprotected sex", "stick to one faithful partner", "convinced me to adjust my sexual practices as I was exposed to the risk factors of the consequences". However some of the participants were adamant in their responses and disagreed vehemently. For example, they commented: "The message of the advertisement is informative but not really convincing, however my sexual choice is my decision", "It did not convince me, need to show more than the risk, make it more creative", and "Not doing enough to scare young people about STD, they make it look trivial".

Yes but the message is brought across in the wrong way. Example on the use of the condom they tell you to pinch the tip and leave an inch. Telling them this is like telling them it is ok to go sex. If the person did not receive a proper sexual education from their parents or friends then they would think that this is the way to go.

Female 25 years old.

No it is not effective it misses out on the consequences of STI's. They act as if HIV is the only STI and they don't show how bad it can get. It is telling us that when and if you get HIV just take your meds and you will be ok. The messages should incorporate the signs and symptoms of the condition. Male 29 years old.

\section{Factors Contributing to Risky Sexual Practices}

Research Question Six: What factors (parental, peer pressure, personal beliefs, social practices, etc.) contribute to risky sexual practices among undergraduate students?

The $t$-value obtained was not statistically significant for the following factors that contribute to risky sexual practices: peer pressure $t=0.089, d f=61, p=0.092$, increased sexual partners due to availability of antiretroviral drugs $t=1.338, d f=61, p=0.006$, regretted having sex after drinking alcohol $t=0.379, d f=61, p=0.786$.

However, the $t$-values were significant for the following factors that contribute to risky sexual practices: parental discussion $t=1.420, d f=61, p=0.004$, end up having sex at social events $t=1.784, d f=61, p=0.000$.

Students were asked if they had been educated on risky sexual practices by their parents. A plethora of views emerged concerning the education received from parents on sexual practices that are risky.

One Student was Visibly Upset when She Recounted Her Experience as a Child:

No, my mother only told me not to have sex, I must pay attention to only school and church. It is my friends I hear talking about their sexual experiences at age thirteen and even then they painted a glamorous picture so naturally I wanted to try it too. I did not have a father figure in my life. Some of the mistakes I made if only my mom sat me down and warned me I would enjoy a better life physically and emotionally. Female 19 years old.

My parents.... no way. Educate me on sex, NEVER. I was educated at school. After my menses she just gave me books to read. Thank God for the teachers who took time out to explain to us about what can happen when you have unprotected sex. Female 20 years old.

No. When I started seeing my menses my mother said do not let anyone touch you. She did not sit me down and talk to me. I wish she did though. She only told me to stay away from boys without telling me why. Female 32 years old.

My mother is a nurse and she tells me everything but didn't tell me not to have sex or use any precautionary measures. She would say things like these: Today a 14 yr old girl came in with syphilis, a what she a have sex for before she keep her body quiet. Well, if them caan hear dem will feel. She did not say daughter do not have unprotected sex and it would lead to syphilis or unwanted pregnancy. She just used whatever condition she cared about and throws it in my face as if I should read between the lines. She gave me pamphlets to read but never sat and discussed it with me. So that's how I guess she educated me about sex and its effects. Female 25 years old.

\section{Discussion of the Results}

The study found that over two - thirds (90.0\%) of the students were sexually active and the male students in- 
itiated their sexual activities earlier than female students. The age of first initiation of sex among the males was 16.1 years and 17.5 years. This result is similar to a study conducted by Hogue, Ntsipe and Mokgatle-Nthabu [41] at the Botswana University, which found that the age of the first initiation of sex among the males and females were 16.5 years and 18.1 years, respectively.

It was revealed that a few of the respondents (12.6\%) had their first sexual encounter when they were less than ten years old. This finding represents a younger age group than was reported in Imaledo, Peter-Kio, and Asuquo [42], in his study which revealed that $33.6 \%$ of the respondents had their first sexual intercourse within the age range of 5 - 19 years. This could have major fertility consequences in the future. It also has some implications for socio-cultural interventions and public education. STIs can have adverse consequences for women's reproductive health, such as pelvic inflammatory disease, infertility and ectopic pregnancy and can hence have a great impact on public health Kaestle, Halpern, Miller, \& Ford, [43]. The age of sexual initiation carries serious implications for STI risk as expressed by Buttmann et al. [44]; Fatusi, and Wang, [45]. Early sexual initiation probably intensifies the length of dangerous experiences during their lifetime. They further purported that the adolescents with early sexual initiation are involved in relationships that are diminutive and engage in multiple partners. When sexual initiation occurs at an early age it carries with it consequences that can affect the individual later in life. The majority (60\%) of the respondents indicated that they had used condom during their first sexual activity. Lower STI occurrence among early condom users enhances the individual's health and diminishes the costs related to the care of one diagnosed with STI and reduces the transmission of infection to others.

The results of this study showed widespread and differential attitudes to the use of condoms among the undergraduate students as $57.1 \%$ did not use a condom, especially among the males. Condom use should be emphasized regardless of one's gender. This kind of practice could be dangerous and there is the possibility of transmitting and spreading sexually transmitted infections including HIV/AIDS.

The current study has indicated that $76 \%$ of the students had more than one sexual partner which is much higher when compared to a study conducted in Benin, Togolese university, which showed that $63 \%$ of students had more than one sexual partner (Ntata, Muula, Siziya, et al., [46]. This kind of behavior could be dangerous and there is a possibility of transmitting and spreading STIs including HIV/AIDS. This may have an adverse impact on the general population in view.

Students' information about sexually transmitted infections was obtained from teachers (12.5\%), friends (11.5\%) and parents (7\%). Interestingly parents featured less frequently as having provided information on sexually transmitted infections. The role of media and teachers in sexual practices awareness promotion needs to be recognized, as the undergraduates appear to rely on mass media as their main source of information This is consistent with the findings of most studies on HIV in Nigeria, which also found the mass media as the primarily source of information (Okonta \& Oseji, [47]).

Parents were not a major source of STIs information as only 7\% of the respondents indicated in Jamaica that they received such information from them. This was much lower than the findings by Asante and Doku [48]. who found that only $27 \%$ of the students received information from their parents. According to Petersen, Bhana and McKay [49], it is also possible that the older generation had not received any information on sex education, making it difficult for them to approach the issue as parents themselves. Furthermore, residential patterns and family structures might reduce the opportunity to discuss sensitive topics like sex. This is further supported by studies conducted by Croft \& Asmussen, [50] and Raffaelli, Bogenschneider \& Flood [51], who indicated that parents' perceptions of their own sexual knowledge often influence/ determine their conversations about sexuality with their children. Such findings underscore the importance for parents to discuss reproductive sexual issues with their children and young adults, because this communicative process is believed to affect their decisions later on in their adult years resulting in a reduction in their risk of HIV infection.

The finding that the respondents experienced different partners which allowed them to keep up with their peers was significant $p=0.000$. As put forward by Ankomah, [52] and Temin, et al. [53], peer pressure was a motivating factor that contributed to females being engaged in transactional sex in order to obtain luxury items, such as expensive clothing, jewellery, fashionable hairstyles, accessories, and makeup.

Factors that may promote unsafe sexual behaviours are partying; along with associated belief that having sex with a virgin will cure STIs including HIV/AIDS. Earning income/gifts by having sex with multiple sex partners, engaging in unprotected sexual intercourse, and relating to different sexual partners in order to keep up with friends are other factors. These actions may inhibit a student's ability to make safe decisions regarding his or her behavior and activities. 
In this study a little over half of the sample (57.6\%) had been tested for STIs. Of the respondents who were tested for STIs (17.4\%) had tested less than three months before the study, and (23.1\%) had tested four - six months ago. The remaining half of participants who tested for STIs did so between seven - 12 months (20.7\%) or more than 12 months ago (38.9\%). The apparent reluctance of the participants to take an STI test could be attributed to fear, stigma and discrimination associated with testing of STI/HIVAIDS respectively. These factors are quite similar to those found by Herman [53], although it must be noted that more students were tested more than a year before in this study. Herman [53], in her study indicated that half of the sample (50.3\%) tested for STI. Of these respondents who were tested for STIs, (22.6\%) had tested less than three months before the study, and one quarter had tested four - six months before $(26.8 \%)$. The other half of the participants who ever tested for STIs had tested either between seven - 12 months (23.2\%) or more than 12 months (27.4\%).

Three limitations were encountered during the conduct of this study. First, the study was carried out at only one university, thus the finding cannot be generalized to the entire population of undergraduate students in Jamaica. The limitation of self-reported data also applies to the current findings, as accuracy of the data cannot be ascertained as a result of the sensitive nature of the subject under the study. A further limitation is that the present study was cross-sectional. Regardless of these limitations this study has relevance and is useful for the university in planning its orientation services and guiding its policies.

The findings in the present study have several implications in terms of health promotion. First, education efforts and wider health promotion and prevention programs targeting young adults need to be put in place. The knowledge gap between the mode of transmission and preventive measures suggests that emphasis should be placed on education and preventive efforts.

Based on the findings the following recommendations are made:

1) HIV/AIDS programs should focus on the consistent use of condoms at each sexual encounter and should emphasize that pills cannot protect a female from being exposed to STIs.

2) Early sexual debut has serious implications and those in authority such as the Ministry of Youth and Culture and Child Development Agency must become involved in campaigns targeting children at an early age to prevent them from engaging in sexual activity at an early age. Health educators should be more involved in HIV/AIDS education and prevention strategies.

3) HIV services should be closely integrated with university communities to correct negative opinions concerning the use of condoms in order to reduce the transmission of HIV/AIDS in our environment.

4) The input of student clubs by designing and implementing awareness and risk reduction sexual activities and promoting peer education is critical.

5) Safer sex education needs to be expanded to include specific areas such as the benefits of practising safer sexual. Specific areas may include appropriate and effective condom use, including the dental dam as well as knowledge of the physical, social, cultural and psychological consequences of inappropriate sexual behaviours. In short, a more comprehensive approach appears to be needed so that students have the knowledge to make suitable and safe decisions.

\section{Conclusions}

In conclusion, safe sexual practices and behaviours are crucial in preventing sexually transmitted infections especially HIV/AIDS with its high morbidity and mortality rate. Undergraduate students are actively engaging in risky sexual practices at a relatively young age, in addition to having an exceptionally high number of sexual partners. These results call for further studies but also strategies that will help students to recognize the consequences of these risky sexual practices, and also help them cope with the inherent challenges including use of condoms, delaying sexual initiation, and decreasing their multiple sexual partners.

The failure to perceive STIs including HIV/AIDS as a personal risk has prevented the majority of the undergraduate students from making commitment to sexual behavior change. Creating awareness of sexual practices in these students will require educational and risk reduction programmes targeting changes in belief and behavior.

\section{References}

[1] Figueroa, J.P., Fox, K. and Minor, K. (1999) A Behaviour Risk Factor Survey in Jamaica. West Indian Medical Jour- 
nal, 28, 9-15.

[2] Crawford, T., Gardner, M.T. and McGrowder, D.A. (2008) A Contemporary Analysis of Sexual Trends and Transmitted Infections among Outpatient at Two Public Hospitals in Jamaica. American Journal of Infectious Diseases, 4, 109-116. http://dx.doi.org/10.3844/ajidsp.2008.109.116

[3] Ministry of Health National HIV/STD Prevention and Control Program Jamaica (1993-2000) In: Crawford, T., Gardner, M.T. and McGrowder, D.A., Eds., A Contemporary Analysis of Sexual Trends and Transmitted Infections among Outpatient at Two Public Hospitals in Jamaica, American Journal of Infectious Diseases, 4, 109-116. http://ezproxy.utech.edu.jm:2075/ehost/pdfviewer/pdfviewer?vid=4\&sid=a58f9d45-8bcb-4888-b6fb-61149cfc20f0\%4 0sessionmgr14\&hid $=122$

[4] Weinstock, H., Berman, S. and Cates, W. (2000) Sexually Transmitted Diseases among American Youth: Incidents and Prevalence Estimates. Perspectives on Sexual and Reproductive Health, 36, 6-10. http://dx.doi.org/10.1363/3600604

[5] Eng. T.R. and Butler, W.T. (1997) The Hidden Epidemic: Confronting Sexually Transmitted Diseases. National Academy Press, Washington, DC.

[6] Global Report (2010) UNAIDS Report on the Global AIDS Epidemic. Geneva: Joint United Nations Programme on HIV/AIDS. http://www.unaids.org/globalreport/documents/20101123_GlobalReport_full_en.pdf

[7] Ministry of Health National HIV/STI Program Jamaica HIV Epidemic Update (2009). http://jamaica-nap.org/pdf/jan-to-June-2008-final.pdf

[8] United States Agency for International Development (2008) Report on Global HIV/AIDS Epidemic. Geneva. In: Durojaiye, C.O., Ed., Knowledge, Attitude and Practice of HIV/AIDS: Behavior Change among Tertiary Education Students in Lagos, Nigeria, 18.

http://eds.a.ebscohost.com.ezproxy.utech.edu.jm/ehost/pdfviewer/pdfviewer?vid=4\&sid=d03af66f-275b-4f20-afd2-a25 d42ee474d\%40sessionmgr4002\&hid=4105

[9] Family Health International Institute for HIV/AIDS (2002) Behaviour Change Communication for HIV/AIDS; A Strategic Framework. Arlington; Family Health International. In: Durojaiye, C.O., Ed., Knowledge, Attitude and Practice of HIV/AIDS: Behavior Change among Tertiary Education Students in Lagos, Nigeria, 18.

http://eds.a.ebscohost.com.ezproxy.utech.edu.jm/ehost/pdfviewer/pdfviewer?vid=4\&sid=d03af66f-275b-4f20-afd2-a25 d42ee474d\%40sessionmgr4002\&hid=4105

[10] Rosenstock, I.M., Strecher, V.J. and Becker, M.H. (1994) The Health Belief Model and HIV Risk Behavior Change. In: DiClemente, R.J. and Peterson, J.L., Eds., Preventing AIDS Theories and Methods of Behavioral Interventions, Plenum Press, New York, 5-24.

[11] Lapinski, M.K. and Witte, K. (1998) Health Communication Campaigns. In: Jackson, L.D. and Duffy, B.K., Eds., Health Communication Research: A Guide to Developments and Directions, Greenwood Press, Westport, 139-161.

[12] Rosenstock, I.M., Strecher, V.J. and Becker, M.H. (1994) The Health Belief Model and HIV Risk Behavior Change. In: Di Clemente, R.J. and Peterson, J.L., Eds., Preventing AIDS Theories and Methods of Behavioral Interventions, Plenum Press, New York, 5-24.

[13] Freimuth, V.S. (1992) Theoretical Foundations of AIDS Media Campaigns. In: Edgar, T., Fitzpatrick, M.A. and Freimuth, V.S., Eds., AIDS: A Communication Perspective, Lawrence Erlbaum Associates, Hillsdale, 91-110.

[14] Michal-Johnson, P. and Bowen, S.P. (1992) The Place of Culture in HIV Education. In: Edgar, T., Fitzpatrick, M.A., and Freimuth, V.S., Eds., AIDS: A Communication Perspective, Lawrence Erlbaum Associates, Hillsdale, 147-172.

[15] Crawford, T., Gardner, M.T. and McGrowder, D.A. (2008) A Contemporary Analysis of Sexual Trends and Transmitted Infections among Outpatient at Two Public Hospitals in Jamaica. American Journal of Infectious Diseases, 4, 109116. http://dx.doi.org/10.3844/ajidsp.2008.109.116

[16] Harding, A.K., Anadu, E.C., Gray, L.A. and Champeau, D.A. (1999) Nigerian University Student's Knowledge, Perceptions, and Behaviours about HIV/AIDS: Are These Students at Risk? The Journal of the Royal Society for the Promotion of Health, 119, 23-31. http://dx.doi.org/10.1177/146642409911900105

[17] Ntata, P.R., Muula, A.S., Siziya, S. and Kayambazinthu, E. (2008) Gender Differences in University Students' HIV/AIDS Related Knowledge and Sexual Behaviours in Malawi: A Pilot Study. Sahara Journal, 5, 201-205. http://dx.doi.org/10.1080/17290376.2008.9724920

[18] Poureslami, M., Roberts, S. and Tavakoli, R. (2001) College Students' Knowledge, Beliefs and Attitudes towards AIDS in Predicting Their Safe Sex Behavior. Eastern Mediterranean Health Journal, 7, 880-894. http://www.freepatentsonline.com/article/College-Student-Journal/201608565.html

[19] Prince, A. and Bernard, A. (1998) Sexual Behaviors and Safer Sex Practices of College Students on a Commuter Campus. Journal of American College Health, 47, 11-21. http://dx.doi.org/10.1080/07448489809595614

[20] Boone, T. and Lefkowitz, E. (2004) Safer Sex and the Health Belief Model: Considering the Contributions of Peer Norms and Socialization Factors. Journal of Psychology \& Human Sexuality, 16, 51-68. 
http://www.freepatentsonline.com/article/College-Student-Journal/201608565.html http://dx.doi.org/10.1300/J056v16n01_04

[21] Wang, Y. and Pillai, V. (2004) AIDS and Culture: A Study of Taiwanese University Students in the United States. Journal of Social Work Research and Evaluation, 5, 41-48

[22] Jemmott, L., Jemmott, J. and Villarruel, A. (2002) Predicting Intentions and Condom Use among Latino College Students. Journal Association Nurses AIDS Care, 13, 59-69. http://dx.doi.org/10.1016/S1055-3290(06)60201-X

[23] Salina, D., Razzano, L. and Lesondak, L. (2000) Influence of Health Beliefs, Attitudes and Concern about HIV/AIDS on Condom Use in College Women. Journal of Prevention Intervention Community, 19, 41-53. http://dx.doi.org/10.1300/J005v19n01_03

[24] Winfield, E.B. and Whaley, A.L. (2002) A Comprehensive Test of the Health Belief Model in the Prediction of Condom Use among African American College Students. Journal of Black Psychology, 28, 330-346. http://dx.doi.org/10.1177/009579802237541

[25] Smith, L. (2003) Partner Influence on Non-Condom Use: Gender and Ethnic Differences. Journal of Sex Research, 40, 346-350. http://dx.doi.org/10.1080/00224490209552200

[26] Conley, T. and Collins, B. (2005) Differences between Condom Users and Condom Nonusers in Their Multidimensional Condom Attitudes. Journal of Applied Social Psychology, 35, 603-620. http://dx.doi.org/10.1111/j.1559-1816.2005.tb02137.x

[27] Duncan, C., Miller, D.M., Borskey, E.J., Fomby, B., Dawson, P. and Davis, L. (2002) Barriers to Safer Sex Practices among African American College Students. Journal of National Medical Association, 94, 944-951.

[28] Ferguson, Y.O., Quinn, S.C., Eng, E. and Sandelowski, M. (2006) The Gender Ratio Imbalance and Its Relationship to Risk of HIV/AIDS among African American Women at Historically Black Colleges and Universities. AIDS Care, 18, 323-331. http://dx.doi.org/10.1080/09540120500162122

[29] Research, Planning, and Institutional Effectiveness (RPIE) (2006) Kent State University. http://www.kent.edu/rpie

[30] Pavlich, H.R., William, A., Dianne Kerr, D.K. and Thompson, A. (2007) Students' Perceptions and Beliefs about Sexually Transmitted Infections. The Health Education Monograph Series, 24, 1-5.

[31] Tangmunkongvorakul, A., Carmichael, G., Banwell, C., Utomo, I.D. and Sleigh, A. (2011) Sexual Perceptions and Practices of Young People in Northern Thailand. Journal of Youth Studies, 14, 315-339. http://dx.doi.org/10.1080/13676261.2010.522562

[32] Herman, J. (2010) South Wales, Australia: The Contribution of Fears and Worries in the Context of Extended Health Belief Model. http://igitur-archive.library.uu.nl/student-theses/2010-0907-202355/3054349\%20Hermans\%20thesis.pdf

[33] Mahoney, C.A., Thombs, D.L. and Ford, O.J. (1995) Health Belief and Self-Efficacy Models: Their Utility in Explaining College Student Condom Use. AIDS Education and Prevention, 7, 37-49.

[34] Baghianimoghaddam, M.H., Rahaii, Z. and Khani, P. (2010) Health Belief Model and HIV/AIDS among High School Female Students in Yazd, Iran. Journal of Research in Medical Sciences, 15, 189-190.

[35] Seloilwe, E.S. (2005) Factors That Influence the Spread of HIV among Students of the University of Botswana. Journal of the Association of Nurses in AIDS Care, 16, 3-10. http://dx.doi.org/10.1016/j.jana.2005.03.003

[36] Abels, M.D. and Blignaut, R.J. (2011) Sexual-Risk Behaviour among Sexually Active First-Year Students at the University of the Western Cape, South Africa. African Journal of AIDS Research, 10, 255-261. http://dx.doi.org/10.2989/16085906.2011.626295

[37] Kaufman, C.E. and Stavrou, S.E. (2002) Bus Fare, Please: The Economics of Sex and Gifts among Adolescents in Urban South Africa. Policy Research Division Working Paper No. 166, Population Council, New York.

[38] MacPhail, C. and Campbell, C. (2001) I Think Condoms Are Good but, I Hate Those Things: Condom Use among Adolescents and Young People in a Southern African Township. Social Science and Medicine, 52, 1613-1627. http://dx.doi.org/10.1016/S0277-9536(00)00272-0

[39] Creswell, J.W. (2008) Educational Research: Planning, Conducting, and Evaluating Quantitative and Qualitative Research. 3rd Edition, Pearson Merrill/Prentice Hall, Boston.

[40] Leedy, P.D. and Ormrod, J.E. (2013) Practical Research: Planning and Design. 10th Edition, Merrill/Prentice Hall, Boston.

[41] Hoque, M., Ntsipe, E. and Mokgatle-Nthabu, M. (2012) Risks of HIV/AIDS and Gender Inequality in Sub-Saharan Africa. Gender \& Behaviour, 10, 4645-4656.

[42] Imaledo, J.A., Peter-Kio, O.B. and Asuquo, E.O. (2012) Pattern of Risky Sexual Behavior and Associated Factors among Undergraduate Students of the University of Port Harcourt, Rivers State, Nigeria. Pan African Medical Journal, 9, 97. 
[43] Kaestle, C.E., Halpern, C.T., Miller, W.C. and Ford, C.A. (2005) Young Age at First Sexual Intercourse and Sexually Transmitted Infections in Adolescents and Young Adults. American Journal of Epidemiology, 161, 774-780. http://dx.doi.org/10.1093/aje/kwi095

[44] Buttmann, N., Nielsen, A., Munk, C., Liaw, K.L. and Kjaer, S.K. (2011) Sexual Risk Taking Behaviour: Prevalence and Associated Factors. A Population-Based Study of 22,000 Danish Men. BMC Public Health, 11, 764. http://dx.doi.org/10.1186/1471-2458-11-764

[45] Fatusi, A.O. and Blum, R.W. (2008) Predictors of Early Sexual Initiation among a Representative Sample of Nigerian Adolescents. BMC Public Health, 8, 136-150. http://dx.doi.org/10.1186/1471-2458-8-136

[46] Ntata, P.R., Muula, A.S., Siziya, S. and Kayambazinthu, E. (2008) Gender Differences in University Students' HIV/AIDS Related Knowledge and Sexual Behaviours in Malawi: A Pilot Study. Sahara Journal, 5, 201-205. http://dx.doi.org/10.1080/17290376.2008.9724920

[47] Okonta, P.I. and Oseji, M.I. (2006) Relationship between Knowledge of HIV/AIDS and Sexual Behavior among In-School Adolescents in Delta State, Nigeria. Nigeria Journal of Clinical Practice, 9, 37-39.

[48] Asante, K.O. and Doku, P.N. (2010) Cultural Adaptation of the Condom Use Self-Efficacy Scale (CUSES) in Ghana. BMC Public Health, 10, 227. http://dx.doi.org/10.1186/1471-2458-10-227

[49] Petersen, I., Bhana, A. and McKay, M. (2005) Sexual Violence and Youth in South Africa: The Need for Community-Based Prevention Interventions. Child Abuse Neglect, 29, 1233-1248. http://dx.doi.org/10.1016/j.chiabu.2005.02.012

[50] Croft, C.A. and Asmussen, L. (1992) Perceptions of Mothers, Youth, and Educators: A Path toward Détente Regarding Sexuality Education. Family Relations, 41, 452-459. http://dx.doi.org/10.2307/585590

[51] Raffaelli, M., Bogenschneider, K. and Flood, M.F. (1998) Parent-Teen Communication about Sexual Topics. Journal of Family Issues, 19, 315-333. http://dx.doi.org/10.1177/019251398019003005

[52] Ankomah, A. (1998) Condom Use in Sexual Exchange Relationships among Young Single Adults in Ghana. AIDS Education Prevention, 10, 303-316.

[53] Temin, M.J., Okonofua, F.E., Omorodion, F.O., Renne, E.P. and Coplan, P. (1999) Perception of Sexual Behaviour and Knowledge about Sexually Transmitted Disease among Adolescents in Benin City, Nigeria. International Family Planning Perspective, 25, 186-190. http://dx.doi.org/10.2307/2991883 
Scientific Research Publishing (SCIRP) is one of the largest Open Access journal publishers. It is currently publishing more than 200 open access, online, peer-reviewed journals covering a wide range of academic disciplines. SCIRP serves the worldwide academic communities and contributes to the progress and application of science with its publication.

Other selected journals from SCIRP are listed as below. Submit your manuscript to us via either submit@scirp.org or Online Submission Portal.
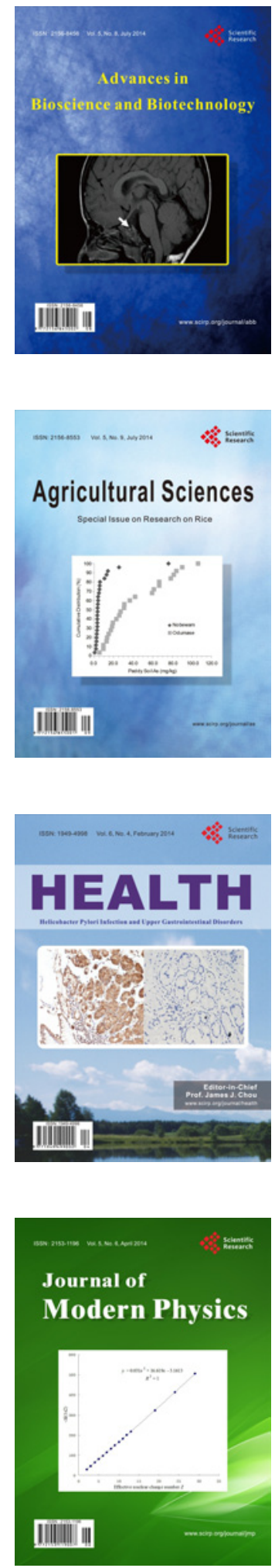
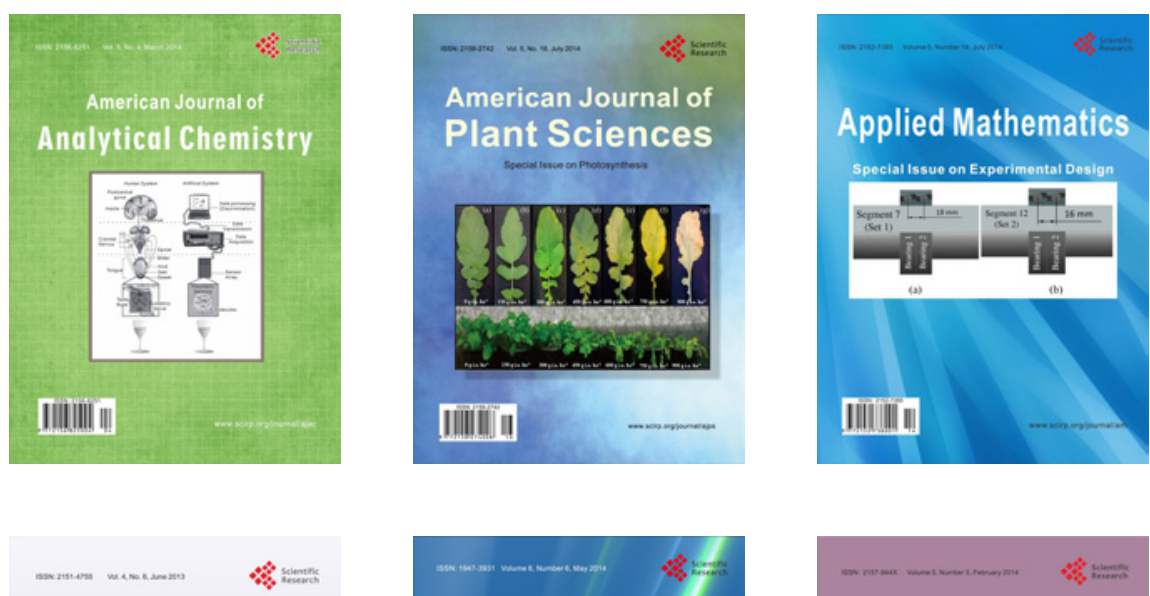

Creative Education
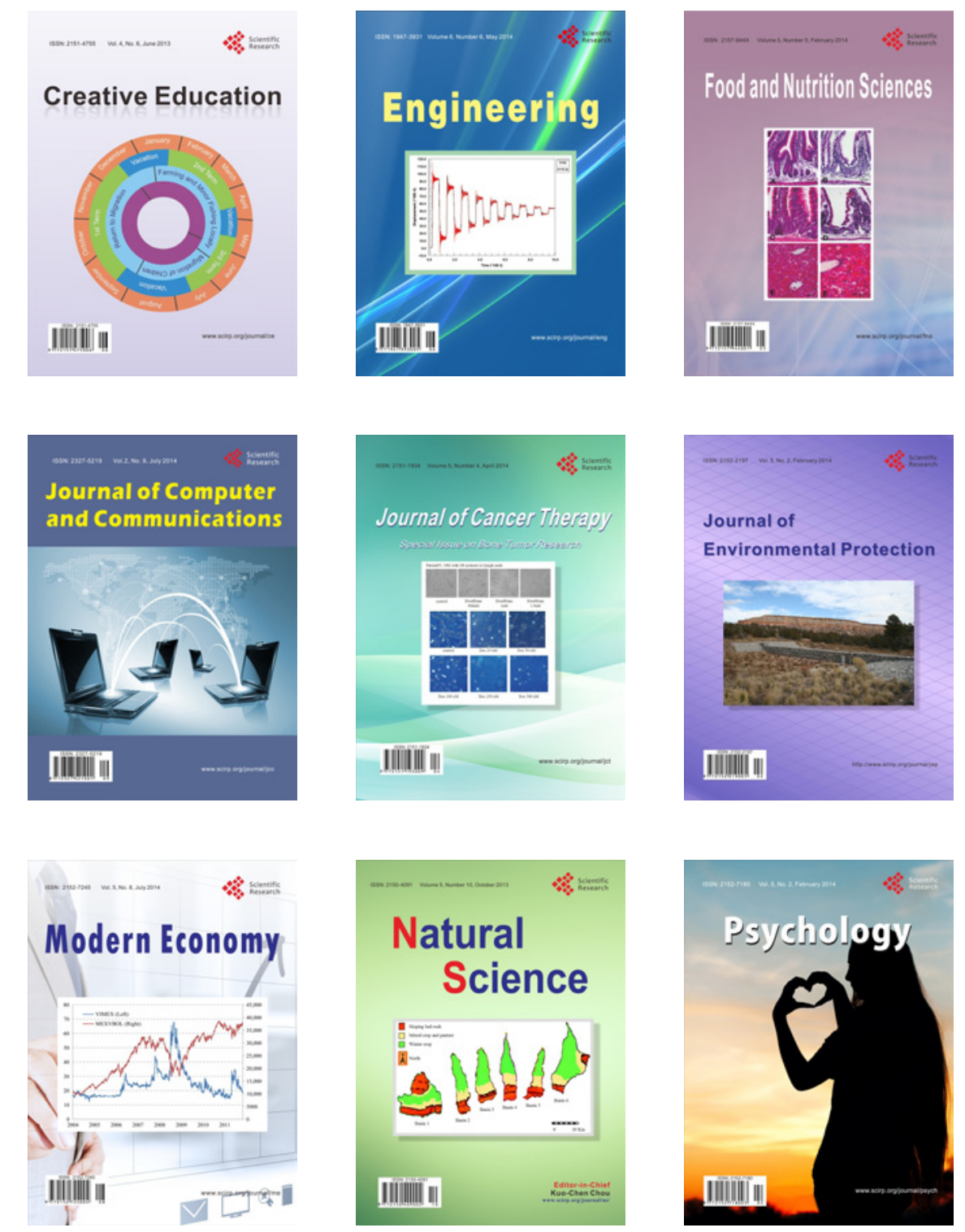